\title{
Prognostic significance of tumour-infiltrating lymphocytes for oestrogen receptor-negative breast cancer without lymph node metastasis
}

\author{
SASAGU KUROZUMI ${ }^{1,2}$, HIROSHI MATSUMOTO ${ }^{1}$, MASAFUMI KUROSUMI ${ }^{3}$, KENICHI INOUE ${ }^{4}$, \\ TAKAAKI FUJII ${ }^{2}$, JUN HORIGUCHI ${ }^{5}$, KEN SHIRABE ${ }^{2}$, TETSUNARI OYAMA ${ }^{6}$ and HIROYUKI KUWANO ${ }^{2}$ \\ ${ }^{1}$ Division of Breast Surgery, Saitama Cancer Center, Saitama 362-0806; ${ }^{2}$ Department of General Surgical Science, Gunma \\ University Graduate School of Medicine, Maebashi, Gunma 371-8511; ${ }^{3}$ Department of Pathology; ${ }^{4}$ Division of Breast \\ Oncology, Saitama Cancer Center, Saitama 362-0806; ${ }^{5}$ Department of Breast Surgery, International University of Health and \\ Welfare, Narita, Chiba 286-8686; ${ }^{6}$ Department of Diagnostic Pathology, Gunma University Graduate School of Medicine, \\ Maebashi, Gunma 371-8511, Japan
}

Received March 29, 2018; Accepted November 15, 2018

DOI: $10.3892 / 01.2019 .9938$

\begin{abstract}
Tumour-infiltrating lymphocytes (TILs) are regarded as significant prognostic markers in patients with breast cancer. However, the prognostic utility of TIL expression based on the intrinsic subtypes has just been identified. The present study investigated the relationship between TIL grades and prognosis in 294 Japanese paitents with breast cancer stratified based on the intrinsic subtypes and clinicopathological characteristics. Stromal TIL status was evaluated using haematoxylin and eosin staining, and TIL grades were categorised into low $(<10 \%)$, intermediate $(\geq 10$ and $\leq 40 \%)$ and high $(>40 \%)$ groups. The relationship between TIL expression and the intrinsic subtypes, clinicopathological characteristics and patient prognosis was analyzed. It was revealed that high TIL expression was correlated with negative oestrogen receptor (ER) expression and high histological grade $(\mathrm{P}<0.001)$. Among the ER-negative patients, the relapse-free survival (RFS) rate of the high-grade TIL group was significantly higher than that of the low-grade TIL group $(\mathrm{P}=0.04)$. Among the ER-negative patients without lymph node metastasis, RFS and cancer-specific survival (CSS) rates of patients with high-grade TILs were significantly higher than the RFS and CSS rates of patients with low-grade TILs $(\mathrm{P}=0.01)$. However, among ER-positive patients, RFS was significantly higher in the low-grade TIL group than in the high-grade TIL group $(\mathrm{P}=0.02)$. In conclusion, TIL expression correlated with ER status and tumour proliferation. High TIL expression was
\end{abstract}

Correspondence to: Dr Sasagu Kurozumi, Department of General Surgical Science, Gunma University Graduate School of Medicine, 3-39-22 Showa-machi, Maebashi, Gunma 371-8511, Japan

E-mail: chachagot-a-mail@hotmail.co.jp

Key words: breast cancer, prognosis, oestrogen receptor, tumour-infiltrating lymphocytes, lymph node metastasis a poor prognostic marker in ER-positive patients but was a good prognostic marker in ER-negative patients. Therefore, the biological association between TILs and primary breast tumours may differ between ER-positive and ER-negative breast cancer.

\section{Introduction}

In immune cell infiltration in breast cancer tissue, the expression of tumour-related immune cells differed greatly among different breast cancer subtypes and patients (1). Lymphocyte-predominant breast cancer (LPBC) is defined as a presentation wherein at least $50 \%$ of the tumour tissue is invaded by tumour-infiltrating lymphocytes (TILs). LPBC was observed in $20 \%$ of triple-negative breast cancers, $16 \%$ of HER2-positive tumours and 6\% of the hormonal receptor (HR)-positive tumours (1). Since the 1970s, studies have attempted to understand the basic function of TILs in cancer as immune response in cancer tissue has been driven by the specific functions of TILs (2). Moreover, the variety of immune cells is believed to contribute to drug sensitivity and prognosis in breast cancer patients. In 2006, Galon et al were the first to report that in situ TIL expression could serve as a strong prognostic marker for colorectal and breast cancer (3). Thereafter, many retrospective studies reported that TIL expression in breast cancer could predict the efficacy of drug therapy and prognosis (4-9). Although the methods to quantify TIL expression and cut-off TIL values in breast cancer tissues varied among studies and have not been clearly standardised, the International Working Group of TILs published the first guidelines for a TIL evaluation in 2014 (10). Accordingly, mononuclear immune cells located between tumour nests, i.e., within the tumour stroma, are defined as stromal TILs (str-TILs). The International TILs Working Group recommended that str-TIL expression should be graded as low (str-TILs: $<10 \%$ ), intermediate (str-TILs: $\geq 10$ and $\leq 40 \%$ ) and high (str-TILs: $>40 \%$ ) based on their relative abundance within the tumour stroma. However, there is no sufficient evidence to 
support the efficacy of this classification. In the present study, we evaluated the relationship of TIL grades with clinicopathological characteristics of breast cancer patients and prognosis based on the guidelines of the International TILs Working Group.

\section{Patients and methods}

Patient background. A total of 294 consecutive female patients, diagnosed as invasive breast cancer who underwent breast-conserving surgery or modified radical mastectomy without neoadjuvant treatment at Saitama Cancer Centre between January 2000 and December 2001, were enrolled in this retrospective study. After the evaluation of intrinsic subtypes, patients with bilateral breast cancer were excluded from the study. Clinicopathological data on pathological tumour size, the status of pathological lymph node metastasis and clinical course were extracted from the patient medical records. This study was conducted in accordance with the Declaration of Helsinki and after the approval by the Institutional Review Board of the Saitama Cancer Centre (nos. 231, 483 and 534). All patients enrolled provided written comprehensive informed consent.

Evaluation of str-TILs. Surgical specimens were fixed in buffered formalin solution, cut to $4-\mu \mathrm{m}$-thick slices and stained with haematoxylin and eosin. Using an optical microscope with $\mathrm{x} 200$ and $\mathrm{x} 400$ magnification, a surgical pathologist specialising in breast pathology (MK) quantified str-TILs. Str-TIL expression was classified into the following three grades per the International TILs Working Group (10) criteria: Low (str-TILs: $<10 \%$ ), intermediate (str-TILs: $\geq 10$ and $\leq 40 \%$ ) and high (str-TILs: $>40 \%$; Fig. 1A-C).

Procedures and evaluation of the expression of oestrogen receptor $(E R)$, progesterone receptor and HER2. The following antibodies were used for immunostaining: 1D5 (Dako, Glostrup, Denmark) for ER, PgR636 (Dako) for progesterone receptor (PgR) and Hercep Test (Dako) for HER2. For evaluation of HER2 gene amplification, dual in situ hybridisation (DISH) was performed with INFORM HER2 Dual ISH DNA Probe Cocktail assay (Ventana Medical Systems, Inc., Tuscon, AZ, USA). ER, PgR and HER2 expression were evaluated in accordance with the American Society of Clinical Oncology and College of American Pathologists $(11,12)$ criteria. In addition, the degree of ER and PgR staining $\geq 1 \%$ and the specimen was determined as positive. The proportional scores of cells membrane HER 2 staining intensity were as follows: scores $0,1+, 2+$ and $3+$. HER2 immunostaining with a score of $2+$ was subjected to a DISH assay to assess the gene amplification of HER2. A HER2 score of 2+/DISH positive or 3+ was defined as HER2-positive cancer. Patients with ER-positive and/or PgR-positive breast cancer were defined as a hormonal receptor (HR)-positive breast cancer.

Statistical analysis. The relationship between TIL grades and various clinicopathological factors, including ER, PgR and HER 2 expression was analysed by Chi-square and Fisher's exact tests. The log-rank test and Kaplan-Meier method were used to estimate relapse-free survival (RFS) and cancer-specific

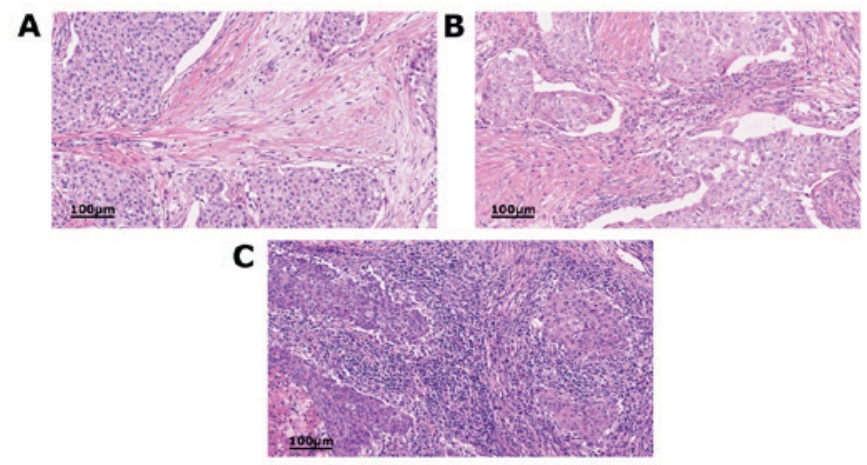

Figure 1. Classification of tumour-infiltrating lymphocytes (TILs) using the criteria of the International TILs Working Group. (A) Low-grade TILs: A few lymphocytes are present in tissue surrounding the cancer nests. (B) Intermediate-grade TILs. (C) High-grade TILs: Numerous lymphocytes are distributed adjacent to the cancer nests.

survival (CSS). RFS was defined as the length of time from the day of surgery to any tumour recurrence (including locoregional recurrence). CSS was defined as the period from the day of surgery until the time of death caused by the progression of breast cancer. In the multivariate analysis, 95\% confidence intervals for the relationship between TIL grades and clinicopathological factors were obtained using a logistic regression test. The relationship between TIL grades and prognosis were obtained using a Cox proportional hazards regression model. Statistical analyses were performed using the SPSS v22.0 software (IBM Corp., Armonk, NY, USA). P $<0.05$ was considered to indicate a statistically significant difference.

\section{Results}

Patient and tumour characteristics. The median age of the 294 patients enrolled in the study was 55 years (age range, 25-87 years). Of these patients, $171(58.2 \%)$ were in postmenopausal state, $134(45.6 \%)$ had positive pathological nodes $(\mathrm{pN}), 162(55.1 \%)$ had a histological grade 3 tumour, $213(72.4 \%)$ had HR-positive breast cancer, 176 (59.8\%) underwent adjuvant endocrine therapy, 158 (53.7\%) underwent adjuvant chemotherapy and $47(16.0 \%)$ were diagnosed with HER2-positive breast cancer (Table I). There were no patients with HER2-positive who received adjuvant trastuzumab therapy since adjuvant trastuzumab administration had not been approved in Japan before 2008 .

Relationship between TIL expression and clinicopathological characteristics. Of the patients assessed, 32 (10.9\%), 44 $(15.0 \%)$ and $218(74.1 \%)$ patients have high, intermediate and low TIL expression, respectively. In both the HER2-negative and HER2-positive patients, only 3.3\% had high TIL expression. In the HR-negative group, $30.9 \%$ had high TIL expression (Table II). The rate of high TIL expression was significantly higher in the HR-negative group than in the HR-positive group $(\mathrm{P}<0.001)$. A univariate analysis identified that the ER $(\mathrm{P}<0.001), \operatorname{PgR}(\mathrm{P}<0.001)$ and HER2 $(\mathrm{P}=0.004)$ status and histological grade $(\mathrm{P}<0.001)$ were significant (Table III). High TIL expression was significantly associated with ER-negative, PgR-negative, HER2-positive and histological grade 3 tumours. On the other hand, multivariate analysis confirmed 
Table I. Patient characteristics.

\begin{tabular}{|c|c|}
\hline Characteristics & Tota \\
\hline \multicolumn{2}{|l|}{ Age, years } \\
\hline$<40$ & \\
\hline$\geq 40$ and $<60$ & 15 \\
\hline$\geq 60$ & 1 \\
\hline \multicolumn{2}{|l|}{ Menopause status } \\
\hline Pre- & 12 \\
\hline Post- & 171 \\
\hline \multicolumn{2}{|l|}{ Type of breast surgery } \\
\hline Breast-conserving surgery & 227 \\
\hline Mastectomy & \\
\hline \multicolumn{2}{|l|}{ Axillary surgery } \\
\hline Sentinel lymph node (biopsy alone) & 14 \\
\hline Axillary lymph node (dissection) & 142 \\
\hline No surgery & \\
\hline \multicolumn{2}{|l|}{ Pathological tumour size } \\
\hline $\mathrm{pT} 1$ & 152 \\
\hline pT2 & 116 \\
\hline pT3 & \\
\hline pT4 & \\
\hline \multicolumn{2}{|l|}{ Pathological nodal status } \\
\hline $\mathrm{pNO}$ & 15 \\
\hline pN1 & \\
\hline $\mathrm{pN} 2$ & \\
\hline pN3 & \\
\hline No surgery & \\
\hline \multicolumn{2}{|l|}{ Pathological TNM stage } \\
\hline \multicolumn{2}{|l|}{ I } \\
\hline \multicolumn{2}{|l|}{ IIA } \\
\hline \multicolumn{2}{|l|}{ IIB } \\
\hline \multicolumn{2}{|l|}{ IIIA } \\
\hline \multicolumn{2}{|l|}{ IIIB } \\
\hline \multicolumn{2}{|l|}{ IIIC } \\
\hline \multicolumn{2}{|l|}{ Not evaluated } \\
\hline \multicolumn{2}{|l|}{ Histological grade } \\
\hline \multicolumn{2}{|l|}{ Grade 1} \\
\hline \multicolumn{2}{|l|}{ Grade 2} \\
\hline \multicolumn{2}{|l|}{ Grade 3} \\
\hline \multicolumn{2}{|l|}{ Oestrogen receptor } \\
\hline \multicolumn{2}{|l|}{ Positive } \\
\hline \multicolumn{2}{|l|}{ Negative } \\
\hline \multicolumn{2}{|l|}{ Progesterone receptor } \\
\hline \multicolumn{2}{|l|}{ Positive } \\
\hline \multicolumn{2}{|l|}{ Negative } \\
\hline \multicolumn{2}{|l|}{ HER2 status } \\
\hline Positive & 47 \\
\hline Negative & 247 \\
\hline
\end{tabular}

TNM, tumor-node-metastasis.

that TIL expression was significantly higher in patients with
ER-negative $(\mathrm{P}<0.001)$ and histological grade $3(\mathrm{P}=0.03)$ tumours (Table III).

Prognostic significance of TIL expression. The analysis identified that the median of RFS was 127 (range, 1-147 months), and median of CSS was 130 (range, 4-149 months). TIL expression was not a significant prognostic factor when the analysis included the entire study cohort of breast cancer patients. Multivariate analysis confirmed that high TIL expression was not an independent prognostic marker (Table IV). TIL expression was not a significant prognostic marker in the HER2-positive breast cancer patient (RFS, $\mathrm{P}=0.67$; CSS, $\mathrm{P}=0.87$; Fig. 2A and B). Additionally, in the HR-positive and HER2-negative breast cancer patients, no significant difference in survival was recognised between the high- and low-grade TIL patients (RFS, $\mathrm{P}=0.50$; $\mathrm{CSS}, \mathrm{P}=0.94$; Fig. $2 \mathrm{C}$ and $\mathrm{D}$ ). Among the triple-negative breast cancer patients, the RFS and CSS were higher in the high-grade TIL group compared with the low-TIL group, although the difference was not significant (RFS, $\mathrm{P}=0.16$; CSS, $\mathrm{P}=0.13$; Fig. 2E and F). By contrast, among the ER-negative breast cancer patients, the RFS was significantly higher in the high-grade TIL group than in the low-grade TIL group (RFS, $\mathrm{P}=0.04$; $\mathrm{CSS}, \mathrm{P}=0.07$; Fig. $3 \mathrm{~A}$ and $\mathrm{B}$ ). Conversely, among the ER-positive breast cancer patients, the RFS was significantly higher in the low-grade TIL group than in the high-grade TIL group with nonsignificant difference in the CSS (RFS, P=0.02; CSS, P=0.18; Fig. 3C and D).

Among the $\mathrm{pN}$-negative patients, none of the cases with a high TIL score had recurrence. Moreover, the RFS and the CCS tended to be higher in the high-grade TIL group than in the low-grade TIL group (RFS, $\mathrm{P}=0.07$; $\mathrm{CSS}, \mathrm{P}=0.10$; Fig. 4A and B). However, TIL expression was not a prognostic indicator in the $\mathrm{pN}$-positive patients (RFS, $\mathrm{P}=0.17$; CSS, $\mathrm{P}=0.14$; Fig. $4 \mathrm{C}$ and D). Among the ER-negative and pN-negative patients, the RFS and CCS were significantly higher in the high-grade TIL group than in the low-grade TIL group (RFS, P=0.01; CSS, P=0.01; Fig. 5A and B). Conversely, TIL expression was not recognised as a prognostic factor in ER-negative and pN-positive patients (RFS, $\mathrm{P}=0.49$; CSS, $\mathrm{P}=0.74$; Fig. 5C and D).

\section{Discussion}

It has been revealed that patients with invasive breast cancer and high TIL expression, those with ER-negative and high histological grade tumours were significantly more common. Moreover, TIL expression level was a strong prognostic marker for ER-negative breast cancer. Among different breast cancer subtypes, ER-negative breast cancer and a subtype with high-grade malignancy exhibit extremely high growth potential. In the Breast International Group (BIG) 2-98 trial, Loi et al reported that TIL expression was a prognostic marker for ER-negative patients, especially those with triple-negative breast cancer (13). Adams et al (14) demonstrated that TIL expression was a strong prognostic marker for triple-negative breast cancer in the Eastern Cooperative Oncology Group (ECOG) 2197 and ECOG 1199 trials. Loi et al (15) conducted an meta-analysis of the efficacy of TIL expression as a prognostic marker in triple-negative breast cancer patients 
Table II. Patient distribution by TIL grades in each breast cancer subtype.

\begin{tabular}{lccrr}
\hline & \multicolumn{4}{c}{ Patients, no. $(\%)$} \\
\cline { 2 - 4 } Subtype & High TIL group & Intermediate TIL group & Low TIL group & Total \\
\hline HR+/HER2- & $6(3.1)$ & $24(12.2)$ & $166(84.7)$ & 196 \\
HR+/HER2+ & $1(5.9)$ & $5(29.4)$ & $11(64.7)$ & 17 \\
HR-/HER2+ & $9(30.0)$ & $6(20.0)$ & $15(50.0)$ & 30 \\
HR-/HER2- & $16(31.4)$ & $9(17.6)$ & $26(50.9)$ & 51 \\
Total & $32(10.9)$ & $44(15.0)$ & $218(74.1)$ & 294 \\
\hline
\end{tabular}

TIL, tumour-infiltrating lymphocyte; HR, hormonal receptor; HER2, human epidermal growth factor receptor type 2.

Table III. The association between TIL grades and clinicopathological characteristics.

\begin{tabular}{|c|c|c|c|c|c|}
\hline \multirow[b]{2}{*}{ Clinicopathological factor } & \multicolumn{3}{|c|}{ Patients, no. } & \multirow{2}{*}{$\begin{array}{c}\begin{array}{c}\text { Univariate } \\
\text { analysis }\end{array} \\
\text { P-value }\end{array}$} & \multirow{2}{*}{$\begin{array}{c}\begin{array}{c}\text { Multivariate } \\
\text { analysis }\end{array} \\
\text { P-value }\end{array}$} \\
\hline & Low TIL group & Intermediate TIL group & High TIL group & & \\
\hline ER status & & & & $<0.001$ & $<0.001$ \\
\hline Positive & 175 & 27 & 5 & & \\
\hline Negative & 43 & 17 & 27 & & \\
\hline PgR status & & & & $<0.001$ & 0.31 \\
\hline Positive & 148 & 26 & 5 & & \\
\hline Negative & 70 & 18 & 27 & & \\
\hline HER2 status & & & & 0.004 & 0.61 \\
\hline Positive & 26 & 11 & 10 & & \\
\hline Negative & 192 & 33 & 22 & & \\
\hline Tumour size & & & & 0.16 & \\
\hline $\mathrm{T} 1-2$ & 191 & 38 & 24 & & \\
\hline $\mathrm{T} 3-4$ & 27 & 6 & 8 & & \\
\hline Nodal status & & & & 0.14 & \\
\hline Negative & 117 & 19 & 12 & & \\
\hline Positive & 101 & 25 & 20 & & \\
\hline Menopausal status & & & & 0.31 & \\
\hline Pre- & 87 & 23 & 13 & & \\
\hline Post- & 131 & 21 & 19 & & \\
\hline Histological grade & & & & $<0.001$ & 0.03 \\
\hline $1-2$ & 116 & 11 & 5 & & \\
\hline 3 & 102 & 33 & 27 & & \\
\hline
\end{tabular}

TIL, tumour-infiltrating lymphocyte; ER, oestrogen receptor; PgR, progesterone receptor; HER2, human epidermal growth factor receptor type 2 .

enrolled in large-scale trials, such as these trials and the Finland Herceptin Trial (FinHER) (16) and reported that TIL expression was a prognostic factor in triple-negative breast cancer. Therefore, most of the studies that showed the efficacy of TIL expression, as a predictor of prognosis and drug efficacy, were retrospective. We believe that a prospective clinical trial is necessary to clarify the real utility of TIL expression as a prognostic marker.
We found that survival was significantly higher in the low-grade TIL group than in the high-grade TIL group among ER-positive breast cancer patients. Recent studies on large cohorts reported that high TIL expression was a poor prognostic factor in ER-positive breast cancer (17). Consistent with these studies, morphological TIL heterogeneity is frequent in ER-positive patients compared with ER-negative patients (18). It is possible that this intra-tumour heterogeneity 
Table IV. Results of univariate and multivariate survival analyses on the influence of clinicopathological variables, including the expression of TILs.

\section{A, RFS}

\begin{tabular}{|c|c|c|c|c|c|}
\hline \multirow[b]{2}{*}{ Clinicopathological factor } & \multicolumn{2}{|c|}{ Univariate analysis } & \multicolumn{3}{|c|}{ Multivariate analysis } \\
\hline & Hazard ratio & P-value & Hazard ratio & $95 \% \mathrm{CI}$ & P-value \\
\hline \multicolumn{6}{|l|}{ TIL expression } \\
\hline Low & \multicolumn{2}{|c|}{ Reference } & \multicolumn{3}{|c|}{ Reference } \\
\hline Intermediate & 0.050 & 0.82 & 0.88 & $0.49-1.61$ & 0.69 \\
\hline High & 0.017 & 0.90 & 0.61 & $0.28-1.30$ & 0.20 \\
\hline \multicolumn{6}{|l|}{ ER status } \\
\hline Positive & \multicolumn{2}{|c|}{ Reference } & \multicolumn{3}{|c|}{ Reference } \\
\hline Negative & 4.68 & 0.03 & 1.05 & $0.55-2.02$ & 0.88 \\
\hline \multicolumn{6}{|l|}{ PgR status } \\
\hline Positive & \multicolumn{2}{|c|}{ Reference } & \multicolumn{3}{|c|}{ Reference } \\
\hline Negative & 8.01 & 0.005 & 1.68 & $0.92-3.07$ & 0.09 \\
\hline \multicolumn{6}{|l|}{ HER2 status } \\
\hline Negative & \multicolumn{2}{|c|}{ Reference } & \multicolumn{3}{|c|}{ Reference } \\
\hline Positive & 9.49 & 0.002 & 1.52 & $0.88-2.61$ & 0.13 \\
\hline \multicolumn{6}{|l|}{ Tumour size } \\
\hline $\mathrm{T} 1-2$ & \multicolumn{2}{|c|}{ Reference } & \multicolumn{3}{|c|}{ Reference } \\
\hline Т 3-4 & 15.13 & $<0.001$ & 1.79 & $0.99-3.23$ & 0.05 \\
\hline \multicolumn{6}{|l|}{ Nodal status } \\
\hline Negative & \multicolumn{2}{|c|}{ Reference } & \multicolumn{3}{|c|}{ Reference } \\
\hline Positive & 29.80 & $<0.001$ & 3.04 & $1.88-4.92$ & $<0.001$ \\
\hline \multicolumn{6}{|l|}{ Histological grade } \\
\hline Grade 1-2 & \multicolumn{2}{|c|}{ Reference } & \multicolumn{3}{|c|}{ Reference } \\
\hline Grade 3 & 5.80 & 0.02 & 1.19 & $0.71-2.00$ & 0.51 \\
\hline
\end{tabular}

$\mathrm{B}, \mathrm{CSS}$

Univariate analysis

Clinicopathological factor

TIL expression

High

Intermediate

Low

ER status

Positive

Negative

PgR status

Positive

Negative

HER2 status

Negative

Positive

Tumour size

T1-2

T3-4
Reference

$0.60 \quad 0.44$

0.11

0.74

0.56

0.54

Reference

9.93

Reference

11.28

$<0.001$

1.60

Reference

4.84

0.03

1.09

Reference

11.51

0.001
Multivariate analysis

$95 \% \mathrm{CI}$

P-value

Reference

0.26-1.21

0.14

$0.24-1.22$

0.14

Reference

$\begin{array}{ll}0.72-3.16 & 0.28\end{array}$

Reference

0.78-3.29 $\quad 0.20$

Reference

0.59-2.02

Reference

1.00-3.81

0.05 
Table IV. Continued.

Univariate analysis (CSS)

Clinicopathological factor
Multivariate analysis (CSS)

\begin{tabular}{lllll}
\hline Hazard ratio & P-value & Hazard ratio & 95\% CI
\end{tabular}

Nodal status

Negative

Reference

Positive

17.93

$<0.001$

2.60

Reference

1.49-4.52

$<0.001$

Histological grade

Grade 1-2

Reference

Grade 3

$9.06 \quad 0.003$

1.56

Reference

$0.85-2.87$

0.15

TILs, tumour-infiltrating lymphocytes; ER, oestrogen receptor; PgR, progesterone receptor; HER2, human epidermal growth factor receptor type 2; RFS, relapse-free survival; CSS, cancer-specific survival; CI, confidence interval.

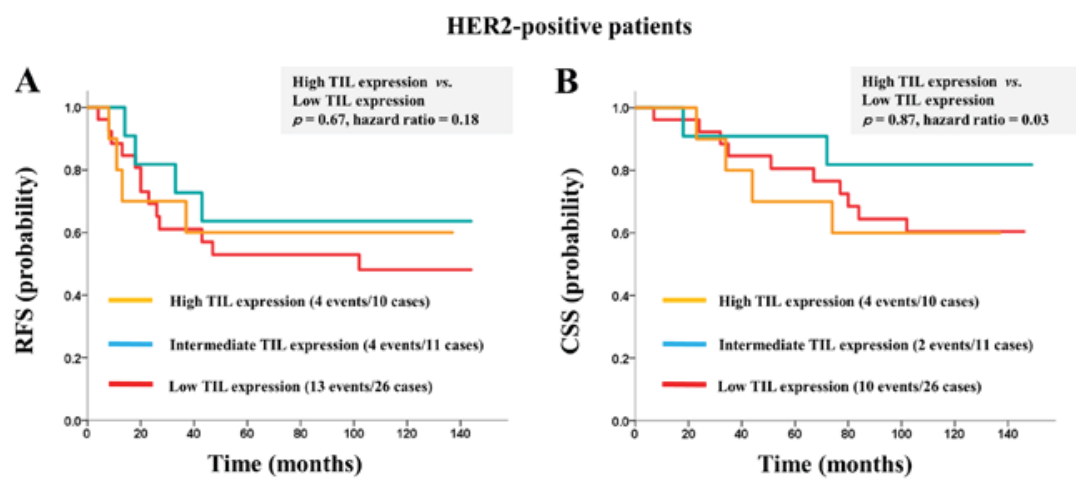

HR-positive and HER2-negative patients
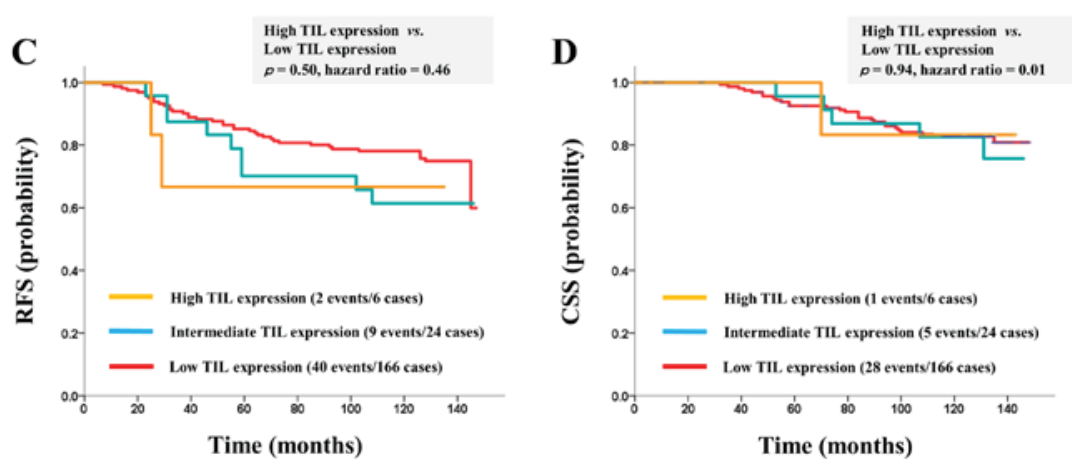

Triple-negative patients
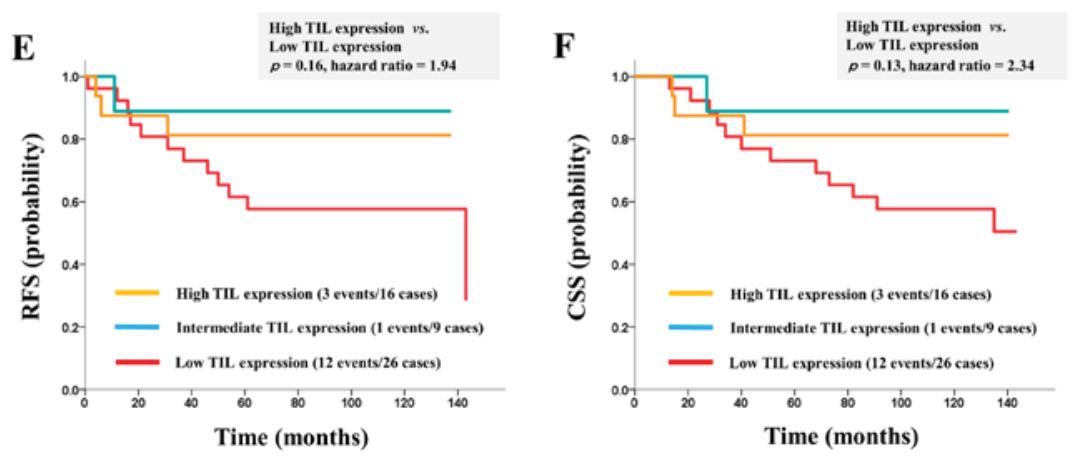

Figure 2. Survival curves of breast cancer subtypes stratified by TIL expression. (A) RFS and (B) CSS curves stratified by TIL expression in HER2-positive patients. (C) RFS and (D) CSS curves stratified by TIL expression in HR-positive and HER2-negative patients. (E) RFS and (F) CSS curves stratified by TIL expression in triple-negative patients. TIL, tumour-infiltrating lymphocyte; RFS, relapse-free survival; CSS, cancer-specific survival; HER2, human epidermal growth factor receptor type 2 ; HR, hormonal receptor. 


\section{ER-negative patients}
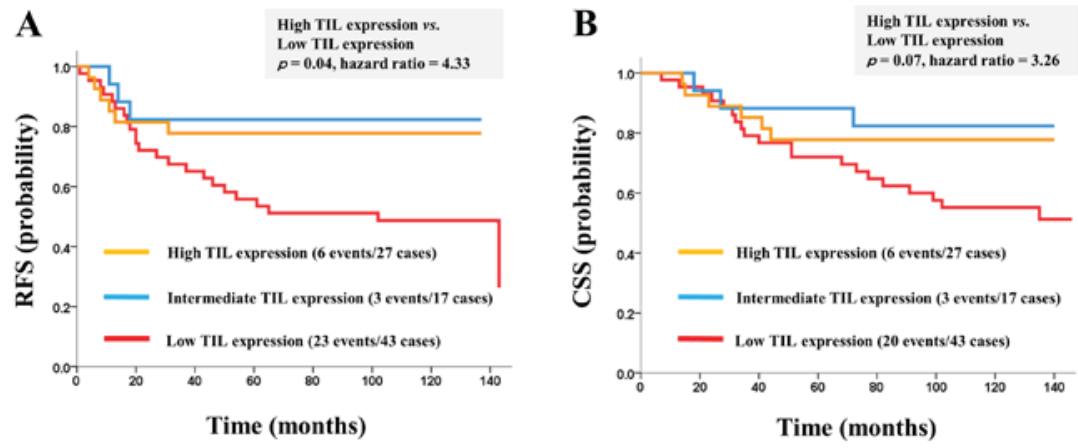

ER-positive patients
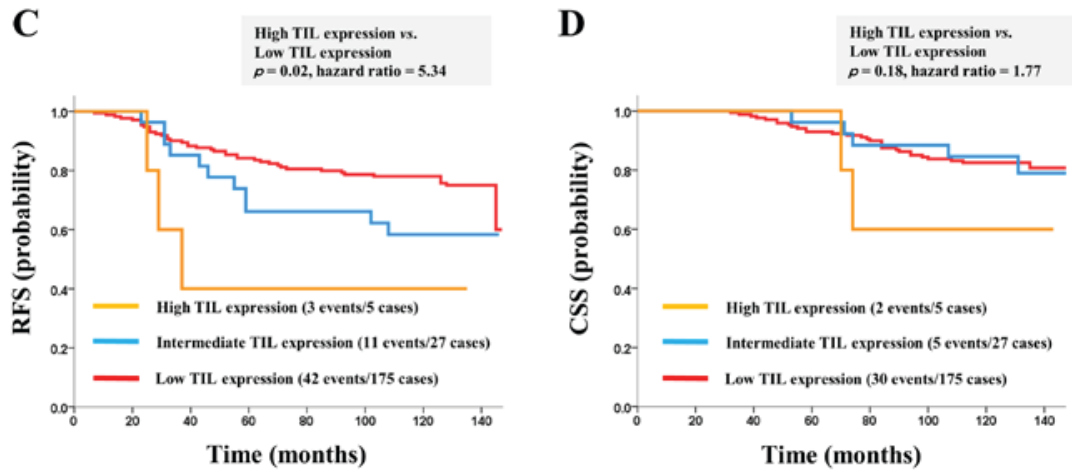

Figure 3. Survival curves stratified by TIL expression and ER status. Comparisons of (A) RFS and (B) CSS between high-grade and low-grade TILs groups in ER-negative patients. The relationship between TIL expression and (C) RFS and (D) CSS in ER-positive breast cancer patients. TIL, tumour-infiltrating lymphocyte; ER, oestrogen receptor; RFS, relapse-free survival; CSS, cancer-specific survival.

\section{Pathological lymph node-negative patients}
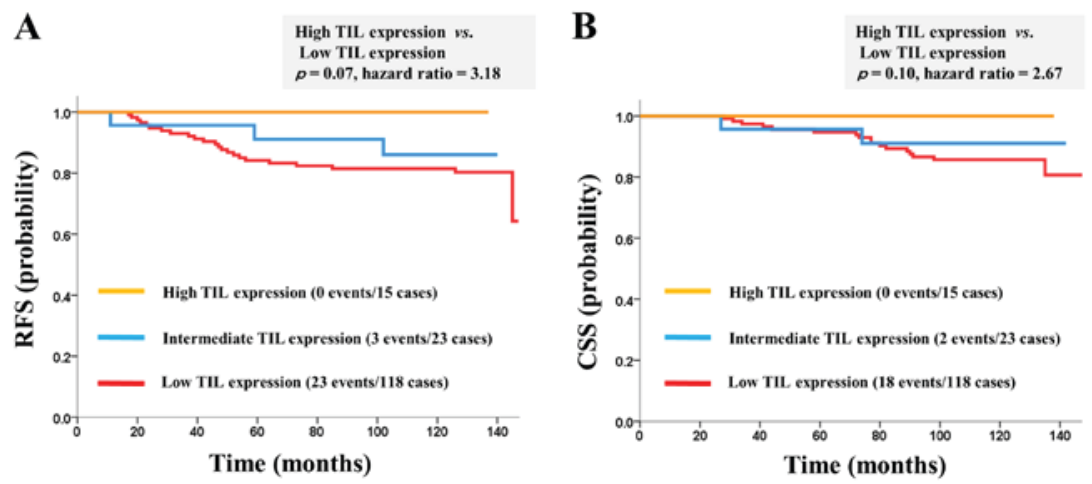

Pathological lymph node-positive patients
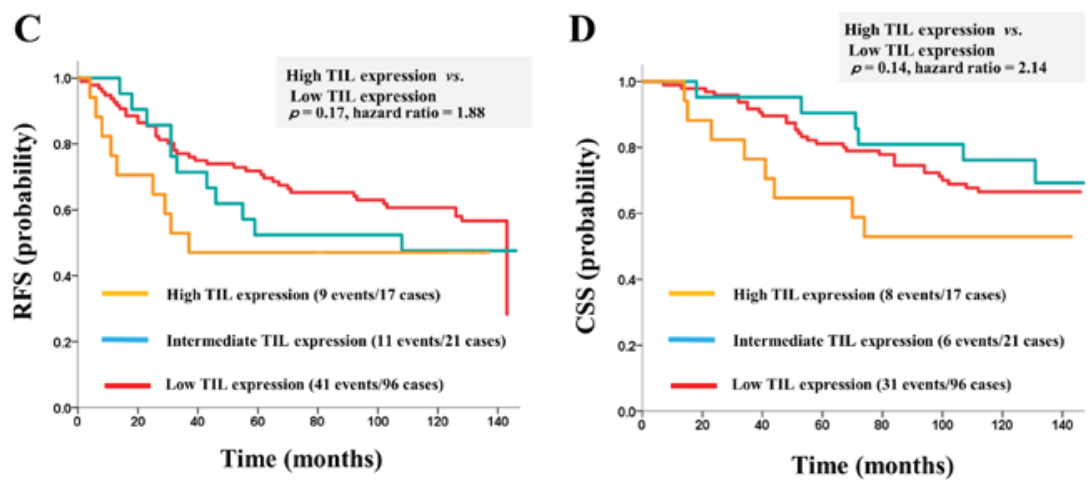

Figure 4. Survival curves stratified by TIL expression and pathological nodal status. Comparisons of (A) RFS and (B) CSS between high-grade and low-grade TIL groups in pathological node-negative patients. The relationship between TIL expression and (C) RFS and (D) CSS in pathological node-positive patients. TIL, tumour-infiltrating lymphocyte; RFS, relapse-free survival; CSS, cancer-specific survival. 

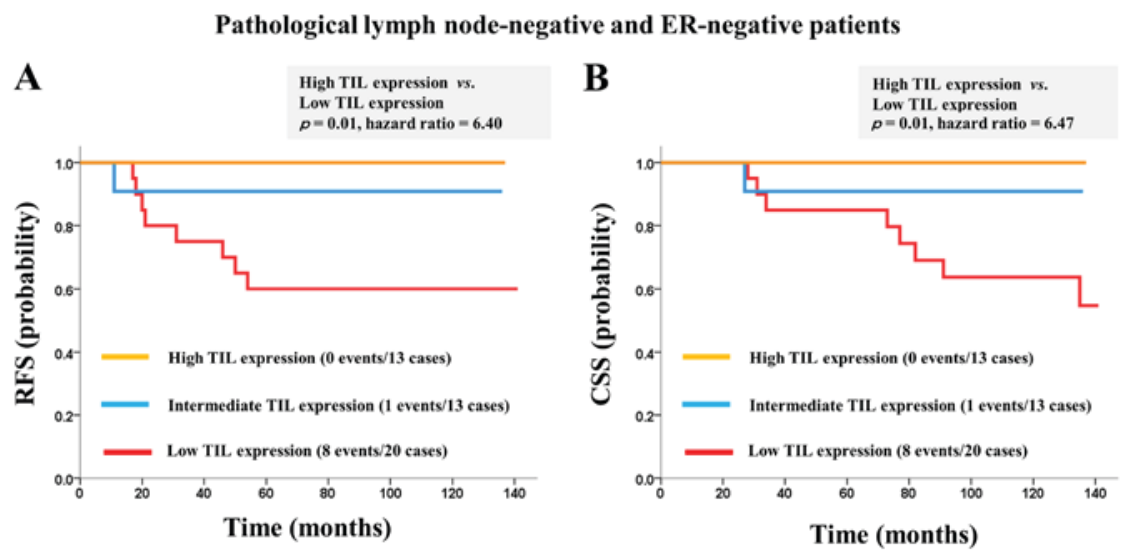

Pathological lymph node-positive and ER-negative patients

C

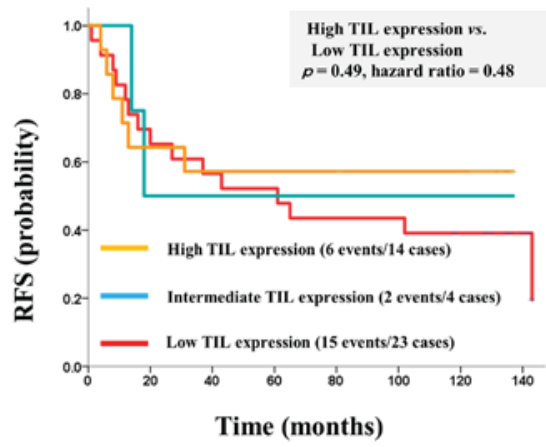

D

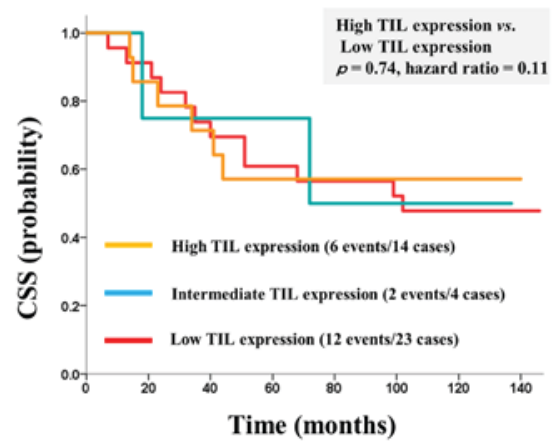

Figure 5. Survival curves stratified by TIL expression and pathological nodal status in ER-negative patients. Comparisons of (A) RFS and (B) CSS between high-grade and low-grade TIL groups in ER-negative and pathological node-negative patients. The relationship between TIL expression and (C) RFS and (D) CSS in ER-negative and pathological node-positive patients. TIL, tumour-infiltrating lymphocyte; ER, oestrogen receptor; RFS, relapse-free survival; CSS, cancer-specific survival.

may affect the expression patterns of immune cells, thereby underlying the difference in the prognostic significance of TIL expression between ER-positive and ER-negative breast cancer patient. To ascertain different roles associated with various TIL types, immunohistochemical analysis of TILs is necessary to determine the distribution of immune cells (19). In addition, the tumour mutational burden is associated with tumour immunity (20) and a high level of the mutational load is associated with poor outcomes in patients with ER-positive tumours $(21,22)$. ER is considered to play an important role in tumour immunosuppression (23) as treatment options for ER-positive and ER-negative breast cancer are distinct. Several clinical studies demonstrated an association between TIL expression and response to chemotherapy (19). Endocrine therapy may modulate immune microenvironment of primary tumours (24); however, relationship of TILs with the response to endocrine therapy in ER-positive breast cancer remains controversial. A grade of ER expression and therapeutic options may affect the extent and the pattern of infiltrating immune cells in the tumour tissue as TIL expression may contribute to different prognostic rates between ER-positive and ER-negative breast cancers. However, there is no clear evidence to support this biological mechanism and the prognostic power of TILs in ER-positive patients with the luminal A and B subtypes. Therefore, further investigation is needed to determine the prognostic utility of TIL expression in ER-positive breast cancer.
It is noted that TIL expression was not a prognostic marker in $\mathrm{pN}$-positive patients. However, among pN-negative patients, the prognosis was better in the high-grade TIL group than in the low-grade TIL group. Lymph node metastasis is an important factor in determining the prognosis of breast cancer patients and the mechanism underlying lymph node metastasis in breast cancer involves various factors. Nonetheless, we propose that a reduced ability of immune cells within the tumour microenvironment, which inhibits cancer cell metastasis is responsible for lymph node metastasis. Programmed cell death protein-1 (PD-1) contributes to the coexistence of cancer cells and immune cells. Moreover, programmed cell death-ligand 1 (PD-L1) inhibits killer T cell activity (25). PD-1 and PD-L1 inhibitors suppress these immune checkpoints, thereby promoting tumour immune response by killer $\mathrm{T}$ cells and exhibiting an anti-tumour effect (26-31). Recent studies were conducted to determine the mechanism by which these molecules interact with cancer invasion and metastasis (32). The expression levels of TILs and immune checkpoint markers in ductal carcinoma in situ provide important information on tumour microenvironment before breast cancer invasion and metastasis. Hendry et al (33) suggested that ductal carcinoma in situ progression into invasive breast cancer has a reduced ability of immune cells in the tumour microenvironment, which inhibits cancer cell invasion caused by PD-1 and PD-L1 activation. Furthermore, Tarhini et al (34) reported 
that PD-L1 expression in melanoma tumour cells contributed to the degree of micrometastasis and sentinel lymph nodes. However, there is still no clear evidence to support whether immune checkpoint factors, such as PD-1 and PD-L1, are involved in axillary lymph node metastasis of breast cancer. Thus, further investigation is required to determine the relationship between lymph node metastasis and tumour immunity in breast cancer.

In conclusions, high TIL expression correlated with negative ER and high histological grade. Among ER-negative patients, survival rate was higher in the high-grade TIL group than the low-grade TIL group. Moreover, TIL expression might be a potent prognostic marker in ER-negative and pN-negative patients. Conversely, among the ER-positive breast cancer patients, survival rate was significantly better in the low-grade TIL group than in the high-grade TIL group. Thus, the biological association of TILs with primary breast tumour might differ between ER-positive and ER-negative breast cancer. The current study revealed that the RFS and the CSS of triple-negative patients tended to be higher in the high-grade TIL group than in the low-grade TIL group without statistical significance. This cause might be due to several factors, which include differences in patient background (race, residence, and familial history) and differences in TIL evaluation method. The number of triple-negative patients was not large in this study. As such, a further study to validate the prognostic utility of TILs based on breast cancer subtypes in large Japanese cohorts is required.

\section{Acknowledgements}

The present study was selected for the Young Investigator Award, 2015 Annual meeting of Japan Surgical Society.

\section{Funding}

No funding was received.

\section{Availability of data and materials}

The datasets used and/or analysed during the current study are available from the corresponding author on reasonable request.

\section{Authors' contributions}

All authors participated in the study design. SK mainly performed image acquisition and statistical analyses. MK assisted SK in histological examinations and evaluating results. KI, HM and MK assisted in the production of the study design and evaluating the results obtained. TF, JH, KS, TO and HK contributed toward the statistical evaluation of results and theoretical organization of the manuscript.

\section{Ethics approval and consent to participate}

The present study was performed following approval from the Institutional Review Board in Saitama Cancer Centre (nos. 231, 483 and 534). Furthermore, the study was performed in accordance with the Declaration of Helsinki, and written informed consent was obtained from all patients prior to inclusion in the study.

\section{Patient consent for publication}

Written informed consent was obtained from all patients prior to inclusion in the study.

\section{Competing interests}

$\mathrm{JH}$ received research funding from CHUGAI Pharmaceutical Co., Ltd. and Taiho Pharmaceutical Co., Ltd. JH received an honoraria from Astra Zeneca K.K. in Japan. All remaining authors have declared that they have no competing interests.

\section{References}

1. Stanton SE, Adams S and Disis ML: Variation in incidence and magnitude of tumor-infiltrating lymphocytes in breast cancer subtypes: A systematic review. JAMA Oncol 2: 1354-1360, 2016.

2. Klein E, Becker S, Svedmyr E, Jondal M and Vánky F: Tumor infiltrating lymphocytes. Ann N Y Acad Sci 276: 207-216, 1976.

3. Galon J, Angell HK, Bedognetti D and Marincola FM: The continuum of cancer immunosurveillance: Prognostic, predictive, and mechanistic signatures. Immunity 39: 11-26, 2013.

4. Savas P, Salgado R, Denkert C, Sotiriou C, Darcy PK, Smyth MJ and Loi S: Clinical relevance of host immunity in breast cancer: From TILs to the clinic. Nat Rev Clin Oncol 13: 228-241, 2016.

5. Salgado R, Denkert C, Campbell C, Savas P, Nuciforo P, Aura C, de AzambujaE,EidtmannH,Ellis CE,Baselga J,etal:Tumor-infiltrating lymphocytes and associations with pathological complete response and event-free survival in HER2-positive early-stage breast cancer treated with lapatinib and trastuzumab: A secondary analysis of the NeoALTTO Trial. JAMA Oncol 1: 448-454, 2015.

6. Denkert C, Loibl S, Noske A, Roller M, Müller BM, Komor M, Budczies J, Darb-Esfahani S, Kronenwett R, Hanusch C, et al: Tumor-associated lymphocytes as an independent predictor of response to neoadjuvant chemotherapy in breast cancer. J Clin Oncol 28: 105-113, 2010.

7. Issa-Nummer Y,Darb-Esfahani S, Loibl S, Kunz G, Nekljudova V, Schrader I, Sinn BV, Ulmer HU, Kronenwett R, Just M, et al: Prospective validation of immunological infiltrate for prediction of response to neoadjuvant chemotherapy in HER2-negative breast cancer-a substudy of the neoadjuvant GeparQuinto trial. PLoS One 8: e79775, 2013.

8. Denkert C, von Minckwitz G, Brase JC, Sinn BV, Gade S, Kronenwett R, Pfitzner BM, Salat C, Loi S, Schmitt WD, et al: Tumor-infiltrating lymphocytes and response to neoadjuvant chemotherapy with or without carboplatin in human epidermal growth factor receptor 2-positive and triple-negative primary breast cancers. J Clin Oncol 33: 983-991, 2015.

9. West NR, Milne K, Truong PT, Macpherson N, Nelson BH and Watson PH: Tumor-infiltrating lymphocytes predict response to anthracycline-based chemotherapy in estrogen receptor-negative breast cancer. Breast Cancer Res 13: R126, 2011.

10. Salgado R,Denkert C,Demaria S, Sirtaine N, Klauschen F,PruneriG, Wienert S, Van den Eynden G, Baehner FL, Penault-Llorca F, et al: The evaluation of tumor-infiltrating lymphocytes (TILs) in breast cancer: Recommendations by an International TILs Working Group 2014. Ann Oncol 26: 259-271, 2014.

11. Hammond ME, Hayes DF, Dowsett M, Allred DC, Hagerty KL, Badve S, Fitzgibbons PL, Francis G, Goldstein NS, Hayes M, et al: American Society of Clinical Oncology/College Of American Pathologists guideline recommendations for immunohistochemical testing of estrogen and progesterone receptors in breast cancer. J Clin Oncol 28: 2784-2795, 2010.

12. Wolff AC, Hammond ME, Hicks DG, Dowsett M, McShane LM, Allison KH, Allred DC, Bartlett JM, Bilous M, Fitzgibbons P, et al: Recommendations for human epidermal growth factor receptor 2 testing in breast cancer: American Society of Clinical Oncology/College of American Pathologists clinical practice guideline update. Arch Pathol Lab Med 138: 241-256, 2014. 
13. Loi S, Sirtaine N, Piette F, Salgado R, Viale G, Van Eenoo F, Rouas G, Francis P, Crown JP, Hitre E, et al: Prognostic and predictive value of tumor-infiltrating lymphocytes in a phase III randomized adjuvant breast cancer trial in node-positive breast cancer comparing the addition of docetaxel to doxorubicin with doxorubicin-based chemotherapy: BIG 02-98. J Clin Oncol 31: 860-867, 2013

14. Adams S, Gray RJ, Demaria S, Goldstein L, Perez EA, Shulman LN, Martino S, Wang M, Jones VE, Saphner TJ, et al: Prognostic value of tumor-infiltrating lymphocytes in triplenegative breast cancers from two phase III randomized adjuvant breast cancer trials: ECOG 2197 and ECOG 1199. J Clin Oncol 32: 2959-2966, 2014.

15. Loi S, Drubay D, Adams S, Francis PA, Joensuu H, Dieci MV, Badve S, Demaria S, Gray R, Piccart MJ, et al: Pooled individual patient data analysis of stromal tumor infiltrating lymphocytes in primary triple negative breast cancer treated with anthracyclinebased chemotherapy. Cancer Res 76 (suppl): abstr S1-03, 2016.

16. Loi S, Michiels S, Salgado R, Sirtaine N, Jose V, Fumagalli D, Kellokumpu-Lehtinen PL, Bono P, Kataja V, Desmedt C, et al: Tumor infiltrating lymphocytes are prognostic in triple negative breast cancer and predictive for trastuzumab benefit in early breast cancer: Results from the FinHER trial. Ann Oncol 25: 1544-1550, 2014.

17. Denkert C, von Minckwitz G, Darb-Esfahani S, Lederer B Heppner BI, Weber KE, Budczies J, Huober J, Klauschen F, Furlanetto J, et al: Tumour-infiltrating lymphocytes and prognosis in different subtypes of breast cancer: A pooled analysis of 3771 patients treated with neoadjuvant therapy. Lancet Oncol 19: 40-50, 2018

18. Heindl A, Sestak I, Naidoo K, Cuzick J, Dowsett M and Yuan Y: Relevance of Spatial Heterogeneity of Immune Infiltration for Predicting Risk of Recurrence After Endocrine Therapy of $\mathrm{ER}^{+}$ Breast Cancer. J Natl Cancer Inst 110, 2018.

19. Kurozumi S, Fujii T, Matsumoto H, Inoue K, Kurosumi M, Horiguchi J and Kuwano H: Significance of evaluating tumor-infiltrating lymphocytes (TILs) and programmed cell death-ligand 1 (PD-L1) expression in breast cancer. Med Mol Morphol 50: 185-194, 2017.

20. Goodman AM, Kato S, Bazhenova L, Patel SP, Frampton GM, Miller V, Stephens PJ, Daniels GA and Kurzrock R: Tumor mutational burden as an independent predictor of response to immunotherapy in diverse cancers. Mol Cancer Ther 16: 2598-2608, 2017.

21. Pereira B, Chin SF, Rueda OM, Vollan HK, Provenzano E, Bardwell HA, Pugh M, Jones L, Russell R, Sammut SJ, et al: The somatic mutation profiles of 2,433 breast cancers refines their genomic and transcriptomic landscapes. Nat Commun 7: 11479, 2016.

22. Haricharan S, Bainbridge MN, Scheet P and Brown PH: Somatic mutation load of estrogen receptor-positive breast tumors predicts overall survival: An analysis of genome sequence data. Breast Cancer Res Treat 146: 211-220, 2014.

23. Svoronos N, Perales-Puchalt A, Allegrezza MJ, Rutkowski MR, Payne KK, Tesone AJ, Nguyen JM, Curiel TJ, Cadungog MG, Singhal S, et al: Tumor cell-independent estrogen signaling drives disease progression through mobilization of myeloid-derived suppressor cells. Cancer Discov 7: 72-85, 2017.
24. Montagna E, Vingiani A, Maisonneuve P, Cancello G, Contaldo F, Pruneri G and Colleoni M: Unfavorable prognostic role of tumor-infiltrating lymphocytes in hormone-receptor positive, HER 2 negative metastatic breast cancer treated with metronomic chemotherapy. Breast 34: 83-88, 2017.

25. Topalian SL, Taube JM, Anders RA and Pardoll DM: Mechanism-driven biomarkers to guide immune checkpoint blockade in cancer therapy. Nat Rev Cancer 16: 275-287, 2016.

26. Larkin J, Chiarion-Sileni V, Gonzalez R, Grob JJ, Cowey CL, Lao CD, Schadendorf D, Dummer R, Smylie M, Rutkowski $\mathrm{P}$, et al: Combined nivolumab and ipilimumab or monotherapy in untreated melanoma. N Engl J Med 373: 23-34, 2015.

27. Brahmer J, Reckamp KL, Baas P, Crinò L, Eberhardt WE, Poddubskaya E, Antonia S, Pluzanski A, Vokes EE, Holgado E, et al: Nivolumab versus docetaxel in advanced squamous-cell nonsmall-cell lung cancer. N Engl J Med 373: 123-135, 2015.

28. Motzer RJ, Rini BI, McDermott DF, Redman BG, Kuzel TM, Harrison MR, Vaishampayan UN, Drabkin HA, George S, Logan TF, et al: Nivolumab for metastatic renal cell carcinoma: Results of a randomized phase II trial. J Clin Oncol 33: 1430-1437, 2015

29. Nanda R, Chow LQ, Dees EC, Berger R, Gupta S, Geva R, Pusztai L, Pathiraja K, Aktan G, Cheng JD, et al: Pembrolizumab in patients with advanced triple-negative breast cancer: Phase $\mathrm{Ib}$ KEYNOTE-012 study. J Clin Oncol 34: 2460-2467, 2016.

30. Gibney GT, Weiner LM and Atkins MB: Predictive biomarkers for checkpoint inhibitor-based immunotherapy. Lancet Oncol 17: e542-e551, 2016.

31. Zhang M, Sun H, Zhao S, Wang Y, Pu H, Wang Y and Zhang Q: Expression of PD-L1 and prognosis in breast cancer: A meta-analysis. Oncotarget 8: 31347-31354, 2017.

32. Soliman H, Khalil F and Antonia S: PD-L1 expression is increased in a subset of basal type breast cancer cells. PLoS One 9: e88557, 2014

33. Hendry S, Pang JB, Byrne DJ, Lakhani SR, Cummings MC, Campbell IG, Mann GB, Gorringe KL and Fox SB: Relationship of the breast ductal carcinoma in situ immune microenvironment with clinicopathological and genetic features. Clin Cancer Res 23: 5210-5217, 2017

34. Tarhini AA, Zahoor H, Yearley JH, Gibson C, Rahman Z, Dubner R, Rao UN, Sander C and Kirkwood JM: Tumor associated PD-L1 expression pattern in microscopically tumor positive sentinel lymph nodes in patients with melanoma. J Transl Med 13: 319,2015 .

This work is licensed under a Creative Commons Attribution-NonCommercial-NoDerivatives 4.0 International (CC BY-NC-ND 4.0) License. 